This article has been published in a revised form in Art Libraries Journal https://doi.org/10.1017/alj.2017.5. This version is free to view and download for private research and study only. Not for re-distribution, re-sale or use in derivative works. (C) Duncan Chappell

\title{
Metaliteracies, Creative Practitioners and Arts Libraries: A Critical Review of the Literature
}

\section{Duncan Chappell}

How do artists, designers, architects and craftspeople seek and deploy information in support of their practice? It is a question that is of central importance to the learning and teaching that arts libraries provide, yet one that has also been subject to much debate within the historical and contemporary literature. An attentive reading of this literature reveals three fundamental metanarratives, each underpinned by a particular epistemology, and it is these narratives that have then informed how institutions construct, embed and assess the teaching of information skills to their readers. Only by critically evaluating the literature is it possible to resituate our own practice and that of our respective institutions within a paradigm that is most appropriate for our particular contexts. It is also possible to identify gaps in our collective professional understanding, in the hope of signposting avenues of research potential for the future.

This critical review is squarely concerned with the information needs, behaviours and learning of creative arts practitioners, and how these have been understood and described by library theorists and practitioners within the literature. The term creative practitioner is here employed to describe individuals who are actively engaged with the disciplines of visual art, architecture, design, media and craft, either through study, employment or leisure. Some associated occupations will naturally fall outside of the boundaries of this review; for a discussion of the information needs of arts administrators for example, the reader is referred to the work of Zach ${ }^{1}$. Similarly, the information requirements of art historians have been comprehensively discussed by Beaudoin ${ }^{2}$, Stam ${ }^{3}$ and others and it is not the intention to replicate such work here. Rather, this review seeks to address a gap in understanding that can be summarised thus: 
there is more research about art historians than artists, perhaps in part because, as academics, art historians are more easily accessible to the LIS scholars and academic librarians who might engage in this type of research. ${ }^{4}$

For in-depth studies of the information needs of creative practitioners, the reader is referred to both Cobbledick ${ }^{5}$ and Hemmig. ${ }^{6}$ However, much has changed in the landscape since the publication of these studies. Although the term information literacy is widely used and understood, the literacies discussed within the literature are now multifarious. Recent years in particular have witnessed a shift away from classical information literacy towards visual literacy, perhaps reflective of the fact that 'literacies change over time as our culture changes' ${ }^{7}$. This shift is exemplified in very concrete terms by the ACRL decision to complement its framework of IL competencies with like competencies for visual literacy, here defined as

A set of abilities that enable an individual to effectively find, interpret, evaluate, use, and create images and visual media... A visually literate individual is both a critical consumer of visual media and a competent contributor to a body of shared knowledge and culture. ${ }^{8}$

For Rockenbach and Fabian, this contemporary shift in focus towards new literacies reflects the age of participation, in which 'creativity on the part of the user, or a desire and ability to contribute as well as consume ${ }^{9}$ are foremost. They note that in today's context 'visual literacy can be understood as a form of critical viewing in much the same way as information literacy can be understood as critical thinking'. ${ }^{10}$ The shift towards a unified ecology of skills across different media reflects discussions on trans- or metaliteracies within the wider LIS literature, in which practitioners are less concerned with 'text literacy and visual literacy and digital literacy in isolation from one another but about the interaction among all these literacies'. ${ }^{11}$

\section{Positivism}

Three distinct epistemologies can be identified through a careful reading of the literature: positivism, constructivism, and socio-cultural or critical theory. As questioning readers, it is incumbent upon us to explore the extent to which these epistemologies have informed or influenced the position of the writers we encounter. Many who write from a positivist 
perspective for example, seek very deliberately to address what they regard as a clear failure in the literature to date, namely a reliance on small-scale, context-specific and subjective data. Mason and Robinson voice the criticism thus:

Such studies as have been done are typically anecdotal in nature, rather than systematic surveys, and limited to small numbers of subjects. This has been variously attributed to the facts that artists are not a clear professional group, that they are difficult to identify and contact for purposes of research, and that they are not thought of as being significant 'consumers' of information, and information products. ${ }^{12}$

In response, positivists have sought to describe information needs and behaviours nomothetically, and have regarded practitioners as subject to a stable objective reality that remains generally consistent across differing institutional or temporal contexts.

For such writers, information needs and behaviours are best studied and understood through empirical observation or the testing of hypotheses, particularly through before-andafter studies or variations from a control. Library interventions are seen to enact a specific change, or at least do so with a high degree of predictive frequency, whilst metaphysical variables such as culture, belief or prior experience are rejected. This approach is demonstrated by Gregory ${ }^{13}$ who, by surveying 165 faculty members across institutions in the US, is able to transform the messiness of human behaviour into easily comprehensible and communicable quantitative data. A similar methodological approach is shown by Mason and Robinson ${ }^{14}$ and Reed and Tanner. ${ }^{15}$ It is nevertheless an approach that comes in for sustained criticism from those of a more constructivist bent, due to its propensity to 'shape the range of possible answers into a narrow stream that cannot extend beyond the researcher's experience or imagination' whilst simultaneously failing to grasp the 'depth, complexity, and idiosyncrasy of human behavior'. ${ }^{16}$

Positivist epistemologies can also be criticised for being overly technicist or normative in their application. Chappell, with his references to employability and the 'cross-transferable information skills that are attractive to employers in an increasingly competitive marketplace ${ }^{\prime 17}$ seems to imply that the information-seeking of creative practitioners is a purely rational activity concerned solely with the maximisation of utility. It is noticeable too 
that the ACRL Visual Literacy Competencies ${ }^{18}$ are written as performance indicators. Constructivists and phenomenologists would squarely reject this stance. Cowan expands on positivist failings thus:

I recognized... that I had developed a conception of information-seeking as a kind of problem-resolution of gap-filling activity. I had assumed information-seeking was an action motivated by a perceived need, a lack, rather than a creative process motivated by curiosity, pleasure or sensory feedback... The phrase 'informationseeking' somehow oversimplifies the creative process, reducing it to a technical problem. ${ }^{19}$

Within the positivist literature one also encounters what we may term the deficiency/deviancy model, in which the information-seeking behaviours of creative practitioners are described by the degree to which they deviate from a supposed norm. Such practitioners find themselves 'in a relationship with the world of recorded knowledge that is very different from the relationship other students are supposed to have with that world'. ${ }^{20}$ The model is highly prevalent and insidious. Even writers such as Stam, who cautions against 'quick judgements about 'good' and 'bad' client behavior', ${ }^{21}$ are actually very quick to pass qualitative judgement on creative practitioners who 'can seldom provide the kind of reasoned information on their needs'. ${ }^{22}$ Cowan challenges the epistemological assumptions of Stam and others by noting

There is ... a tacit assumption that there is a correct way to use libraries, and a strong thread of belief that artists deviate from this correct usage. They are therefore considered to be inadequate and inefficient library users. ${ }^{23}$

For Cowan, this is particularly true when browsing is discussed. She reacts against writers such as Avann ${ }^{24}$ (who describes browsing as ineffective and slow) for their failure to give credence to purposive browsing, noting that 'browsing is consistently mentioned as if it were a flawed information-seeking technique, and an inadequacy on the part of the artists' ${ }^{25}$ For further discussion on the forms of browsing used by creative practitioners, the reader is referred to Bawden ${ }^{26}$ and Pacey. ${ }^{27}$

\section{Constructivism}


The literature is equally characterised by a second prevailing epistemology: constructivism. For constructivist writers, reality is inherently perspectival with few universal laws that apply equally across groups or contexts. Instead, these authors are interested in observing and describing the implicit experiences of individuals in order to render them explicit. Their research focus lies in the qualitatively different ways that creative practitioners experience, conceptualise, perceive and understand phenomena. Underpinning their research is a tacit belief that behaviour is context-dependent, and that agentive minds negotiate and construct meaning for themselves, rather than having knowledge bestowed upon them. Rockenbach and Fabian describe constructivism thus:

An important aspect of the constructivist approach is its inherently non-linear structure resulting from inquiry that is directed by the learner, not the facilitator. The learner's prior knowledge forms the basis for the discovery process, which grows from their frame of visual references. ${ }^{28}$

Schiff ${ }^{29}$ observes that creative practitioners bridge discontinuities in their knowledge of experience through step-takings, observable behaviours that are deployed as they construct their reality. To understand how the step-taking process occurs, professionals must shift their focus towards situated cognition and consider not just what individuals learn, but how. She advocates cognitive apprenticeships in which students are enabled to learn through activities that are authentic to both their lived experience and domain specialism. Due to their 'ethnographic depth, and ...contextualized, narrative-based and dialogic nature', ${ }^{30}$ Cowan advocates the use of interviews to explore and understand the sensemaking of practitioners.

Jiao and Onwuegbuzie provide an important insight into the correlation of library anxiety and learning modalities ('the manners in which individuals typically acquire, retain, and retrieve information' $\left.{ }^{31}\right)$. They find that those individuals with a primarily visual modality are more likely to experience affective barriers such as insecurity, and are significantly less comfortable asking the library for help. Van Zijl and Gericke concur that creative practitioners rely heavily upon their peers for advice, support and guidance, observing that 'it would be remiss not to mention the importance of the invisible college of colleagues, fellow artists and art scholars in a discussion of the information-seeking needs and behaviours of visual artists' ${ }^{32}$ 
Rom $^{33}$ notes that the activities of creative practitioners are directed not only by logic, but by inspiration, imagination, intuition and serendipity. Frank ${ }^{34}$ finds that aesthetic considerations such as colour, line and space impact upon the resources that creative practitioners will either engage with or not. Realising that library interventions at Oakland University were characterised by a 'disassociation with hands-on artmaking', Greer has sought to bridge the gap by incorporating 'nontraditional, creative learning activities' ${ }^{35}$ such as bookmaking and think-share-pair. At Yale, Bliss and Rockenbach have employed problembased learning 'to make sessions both relevant and practical by using real-world problems and encouraging students to take the initiative'.$^{36}$ Elsewhere ${ }^{37}$ the power of discussion as a pedagogical tool is discussed, mirroring as it does the participatory dynamics seen in the studio crit.

\section{Socio-Cultural and Critical Theory}

Any circumspect review must of course recognise that all bodies of literature carry within them some inherent biases. Of the sources identified for this review, nearly all were written from UK or US socio-cultural contexts, with very little offering a non-Western perspective. The critical reader may rightly question whether the conclusions that positivists or constructivists reach would necessarily hold true if exposed to different cultural contexts and histories. Despite the foundational work of a few researchers (Van Zijl and Gericke ${ }^{38}$, Lo and $\mathrm{Chu}^{39}$ ), comprehensive research from a socio-cultural perspective is sadly lacking, and much needed.

Nevertheless, a few writers have tentatively sought to explore how cultural orientations may shape what people look for and how they go about doing so. Schiff ${ }^{40}$ discusses the impact that disability can exercise not only upon the information an artist requires, but also upon the format and mode of delivery. Despite the increased visibility of disability as a social construct in recent years, little else is available that considers its influence on information provision for creative practitioners.

Van Zijl and Gerickes' ${ }^{41}$ survey of 15 art and design lecturers at Vaal Triangle Technikon in South Africa is notable for its attempt to consider, at least in part, the effects of prior academic attainment, age and gender. The authors conclude that the information sources preferred by men and women are widely divergent within the local context, with women 
more heavily reliant on the library and their own print collections and men much more likely to use electronic sources. Younger people too are more likely to embrace online resources. Though the study does suffer from some marked weaknesses in parameters (no students are included, and the issue of race is not considered), the study does at least provide a template for future studies that wish to consider the under-researched influence of sociocultural factors.

If Van Zijl and Gericke fail to consider race, Graveline provides a rare but notable attempt to explore its effect from a critical theory perspective. Her discussion is unapologetically perspectival, and provides a proactively political call to action. Noting that many African American artists remain culturally isolated, she asserts that 'the librarian should bridge the gap by making the first contact' to enable these artists to 'bridge the duality of their existence as a minority within a majority culture'. ${ }^{42}$ This will, at times, require the librarian to assume the role of mentor to individuals, or to take affirmative action by employing African American peer assistants in the library. Her discussion of how minority students may utilise a high-context learning style that is at variance with the low-context style commonly used in US instruction is insightful, and surely worthy of further empirical study.

Similarly writing from a critical theory perspective, Pawley invites us to cultivate a questioning approach to information literacy in which skills acquisition is itself rejected as a reflection of an increasingly commodifying and neoliberal agenda in the social and governmental realms. She asserts that

Rather than focusing only on negotiating some essentialist concept of the term and on the best techniques for transmitting the agreed-upon skills, we should also be debating what, fundamentally, we are trying to do when we engage in information literacy practices, however defined. ${ }^{43}$

Such calls stand in stark contrast to both the positivist and constructivist epistemologies, and invite us to revisit and question the dominant forces and hidden assumptions that influence what we do as library practitioners.

\section{Models of Embeddedness}


The literature has much to say on the how of information literacy provision within an art and design context. An analysis of the studies to date reveals 3 distinct models (standalone model, programme-embedded and curriculum-embedded) that institutions choose either to adopt or dismiss according to their local requirements and cultural contexts.

Walczak, Sammet and Reuter describe a standalone model characterised by 'one-shot, single sessions isolated from the broader curriculum with little or no follow-up instruction' ${ }^{44}$ Halverson and Volker ${ }^{45}$ of the California Institute of the Arts discuss Critical Studies 114, that though professionally benchmarked is taught squarely by librarians and is not mandatory.

Such a model has been subject to sustained criticism within the literature, with many writers concurring with Gregory's contention that

General sessions are not always helpful to art students who may struggle to see the relevance... if it is not directly applicable to art, and they may forget the information as soon as they walk out of the library. ${ }^{46}$

Avann and Wood, for example, assert that

Any programme of user education will be doomed to failure unless it is relevant to the user's need at the time when it is offered; is integrated with studies; and proves itself to be of use when applied by the student later. ${ }^{47}$

In recent years, such criticism has led many institutions to abandon completely their standalone inductions and workshops. Rom and Lantz sound a note of caution however:

The too-often-slighted tour of the facility is a significant entrée for our artiststudents' explorations, showing them the physical locations of the library's resources; familiarity with the physical environment is more important to art students than librarians generally acknowledge. ${ }^{48}$

Responding to the perceived weaknesses of the standalone model, many institutions (California Institute of the $\mathrm{Arts}^{49}$, Clemson University ${ }^{50}$, University of Virginia ${ }^{51}$, Washington University in St Louis ${ }^{52}$ ) have sought to resituate their practice within core academic programmes. At Oakland University Greer, recognising that 'library sessions were often completely disconnected from... daily academic experiences' sought to resituate her 
interventions as part of a 'scaffolded program of instruction' ${ }^{53}$ Bliss and Rockenbach ${ }^{54}$ describe the process by which standalone workshops at Yale School of Architecture were reformulated so that they were better tied to the curriculum. Central to their efforts was close working with faculty, which lead to the eventual mandating of library workshops for all graduates and postgraduates. McGuinness ${ }^{55}$ advocates the co-opting of academic champions who are favourably disposed towards the library's interventions, and provides strategies for doing so. At Moore College of Art such 'participation imbued the assignment with a validity it might have lacked had the librarian delivered the same information alone' ${ }^{56}$ But for this to be impactful, a clear understanding of the respective responsibilities of partners is paramount:

Setting up research standards should be the shared responsibility of the course instructor and the librarian. The responsibility of the instructor is to evaluate the students for course content, whilst the responsibility of the librarian is to teach the students how to find and use information to achieve success in the course. ${ }^{57}$

Some practitioners and writers have begun to push the boundaries of this programmeembedded model still further, in order to integrate library interventions even more systemically across the curriculum as a whole. Haines ${ }^{58}$ discusses the practice of field librarianship and how it has enabled her to understand better the wider curricula of art and design, across the piece, within the University of Michigan. Situating herself both physically and cognitively outside of the library and within faculty, she can be present at meetings and discussions, sit in on classroom activities, and involved directly in teaching across programmes. Salisbury and Ellis ${ }^{59}$ discuss their experiences with the faculty of arts at the University of Melbourne, and describe how they developed a framework to translate institution-wide policy into learning outcomes that are then applied across the curriculum.

Walczak, Sammet and Reuter are perhaps the strongest proponents of institutionallymandated, curriculum-embedded interventions, asserting that the academic champions described by McGuinness can only ever bring intermittent success as results are based upon personalities. At the Art Institute of Lauderdale, an IL task force was instead formed with eight representatives from academic, library and support departments charged with developing shared training and learning outcomes. They assert that learning outcomes need to be integrated horizontally across the curriculum from art to zoology and vertically 
throughout the college years' ${ }^{60}$ However, the more constructivist or phenomenologically inclined practitioner may question the degree to which this model is capable of accommodating difference and variation in learning modalities across subjects.

\section{Evaluative Methodologies}

The literature is sadly characterised by a lack of methodologically-sound post-activity evaluation. Most studies rely purely on observational or anecdotal evidence; Stylianopoulos ${ }^{61}$ for example is not uncommon in claiming an increased confidence in users without offering evidence beyond the anecdotal to support this. We can only conjecture that this perhaps illustrates a lack of skill or confidence in research methodologies within arts librarianship, which our professional bodies might reflect upon. Halverson voices a concern that the lack of such a culture of evidence risks undermining our ultimate effectiveness:

If, through the meaningful application of assessment tools, one is able to establish a 'culture of evidence' in an IL program, which in practical terms means one is applying assessment tools for the purposes of looking closely at what is being done, then one is in a position to work toward continuous improvement. And without continuous improvement, one cannot expect to have a cohesive, living information literacy program. ${ }^{62}$

Of those researchers who do attempt post-activity evaluation, most seek to demonstrate effectiveness either through improved attainment or changed behaviour, and it is generally the case that those who are concerned with attainment lean towards quantitative design frames, whilst those who are concerned with behavioural change rely upon qualitative methodologies.

Turning first to improved attainment, many researchers rely upon external frameworks in order to assess students both pre- and post-activity. Bliss and Rockenbach ${ }^{63}$ and Zanin-Yost and Tapley ${ }^{64}$ duly incorporate ACRL Information Literacy Competencies ${ }^{65}$ into their course outcomes. In the UK, Chappell ${ }^{66}$ maps against frameworks from both the library and education sectors, including QAA Subject Benchmarks ${ }^{67}$ for art and design, ARLIS/NA Information Competencies ${ }^{68}$ for design, and SCONUL Seven Pillars. ${ }^{69}$ 
Vecchiola stresses that though such standards are useful for their 'chronological skillsbuilding arrangement of basic, intermediate, and advanced', they should nevertheless be mediated and re-presented, particularly to faculty. She advises that frameworks that are 'developed within library professional organizations and are of peripheral importance to faculty, should be filtered through subject librarians' professional practice rather than shared as they exist'. ${ }^{70}$ To assist in this mediation, Ball et al. ${ }^{71}$ provide practical advice on creating one's own competency standards for art and design (within a US context) and then aligning these to curricula. Walczak, Sammet and Reuter ${ }^{72}$ discuss the decision by the Art Institute of Lauderdale to reject generic ACRL standards in favour of a more context-specific approach in which the most appropriate skills for their particular students are foregrounded. Halverson of the California Institute of the Arts shares the view that though the ACRL framework can provide useful parameters it should not be slavishly adopted, pointedly noting that 'what is viewed as academic 'output' at an arts school, is perhaps not measurable in standard ways'. Instead, she asks

How do we make accreditation standards and national learning objectives work in a meaningful way as they are being applied to students who by nature are arguably different than traditional university students? ${ }^{73}$

Compared to the measure of increased attainment, sustained behavioural change has tended to prove more difficult to study and measure. This is, no doubt, due to the methodological complexities of sustaining access to participants over the longer term, but is also perhaps also a reflection of curricula pressures and a lack of 'opportunities for subsequent reinforcement' ${ }^{74}$ Wayne measures graduate architecture students at the University of California at Berkeley across two semesters in order to demonstrate the behavioural change brought about by attendance at library workshops. He reports that all participants now use the library, and that their use of journals and indexes has increased dramatically. Indeed, ten of the 15 participants report that the workshops have 'led them to sources that ultimately made a difference in the overall quality of their design product'. ${ }^{75}$

Dissatisfied however with the perceived shortcomings of these evaluative approaches, Salisbury and Ellis instead co-opt an evaluative framework from business, observing that 
It was necessary to move beyond an evaluation process that relied on participant perceptions of a session. We recognized a need to verify that students did acquire skills and knowledge as a result of our efforts. ${ }^{76}$

Here, the authors evaluate participant learning through the lens of Kirkpatrick's ${ }^{77}$ four levels: reaction (immediate response), learning (changed attitudes, improved knowledge or increased skills), behaviour (long-term adaptation), and results (organisational impact). Pointedly noting that initial results in reaction do not necessarily prove effective learning, they deploy a pre- and post-activity test so that 'any measured difference in knowledge and skills can be attributed to the intervention' ${ }^{78}$ Post-activity, the ability to correctly identify different types of citation rose from $73 \%$ to $91 \%$, but more involved tasks demonstrated a lower level of improvement, causing the authors to conclude that 'when conceptual understanding became more complex... students exhibited a much lower rate of improvement'. ${ }^{79}$

The critical reader may question whether causal links are ever so simply ascribed, and whether the methodology is able to account for other, perhaps unseen, agents that act upon the participants. On a fundamental level also, the critical theorists would remind us that effectiveness and improvement are both epistemologically-loaded terms and are seldom, in themselves, value-neutral.

\section{Conclusion}

Although generally described as a more difficult group to study than art historians, research on the information needs and behaviours of creative practitioners has noticeable increased in recent years, with around 97 identified studies. These have heightened our understanding of creative practitioners, who may require a proactively different approach from us and our libraries. However, research in the area remains somewhat disparate and uncoordinated, and heavily reliant upon anecdotal evidence. Although several writers highlight the need for sustained longitudinal data, such data is as yet unforthcoming. There remains an evident need for larger-scale studies, sustained longitudinally, that are better able to isolate and determine the true impact of library instruction on behavioural change within differing contexts. Such studies would invariably require resources and coordination beyond that available to single practitioners or institutions. Yet, the developing field of learning analytics 
and their application, at least within the higher education environment, may eventually provide the infrastructure necessary to conduct such research.

There is an evident need too for further socio-cultural research within the field, which is presently poorly served by perhaps just 4 or 5 representative studies. The effect of gender, race, sexuality, disability and socio-economic background on the needs and behaviours of creative practitioners has, at best, been merely touched upon. By expanding our collective horizons beyond the positivist/constructive dichotomy, such research would provide a highly useful service to both ourselves and our patrons.

\section{Duncan Chappell}

Academic Liaison Librarian

Glasgow School of Art

164 Renfrew Street

Glasgow G3 6RF

UK

Email: d.chappell@gsa.ac.uk

\footnotetext{
${ }^{1}$ L. Zach, "When is 'enough' enough? Modelling the information seeking and stopping behaviour of senior arts administrators", Journal of the American Society for Information Science and Technology 56(1) (2005): 23-35

2 J. Beaudoin, "Image and text: a review of the literature concerning the information needs and research behaviours of art historians", Art Documentation 24(2) (2005): 34-37

${ }^{3}$ D. C. Stam, "Tracking art historians: on information needs and information-seeking behaviour", Art Libraries Journal 14(3) (1989): 13-16

${ }^{4}$ S. Cowan, "Informing visual poetry: information needs and sources of artists", Art Documentation 23(2) (2004): 14

${ }^{5}$ S. Cobbledick, "The information-seeking behaviour of artists: exploratory interviews", Library Quarterly 66(4) (1996): 343-372

${ }^{6}$ W. S. Hemmig, "The information-seeking behaviour of visual artists: a literature review", Journal of Documentation, 64(3) (2008): 343-362

${ }^{7}$ B. Rockenbach \& C. A. Fabian, "Visual literacy in the age of participation", Art Documentation 27(2) (2008): 27

${ }^{8}$ Association of College \& Research Libraries, Visual Literacy Competency Standards for Higher Education (Chicago: ACRL, 2011), Available http://www.ala.org/acrl/standards/visualliteracy
} 
${ }^{9}$ Rockenbach \& Fabian, "Visual literacy", 26
${ }^{10}$ Rockenbach \& Fabian, "Visual literacy", 29
${ }^{11}$ T. Ipri, “Introducing transliteracy: what does it mean to academic libraries?", College \& Research Libraries News 71(10) (2010): 532

${ }^{12} \mathrm{H}$. Mason \& L. Robinson, "The information-related behaviour of emerging artists and designers: inspiration and guidance for new practitioners", Journal of Documentation 67(1) (2011): 160

${ }^{13}$ T. Gregory, "Under-served or under-surveyed: the information needs of studio art faculty in the South Western United States", Art Documentation 26(2) (2007): 57-66

${ }^{14}$ Mason \& Robinson, "The information-related behaviour", 159-180

${ }^{15}$ B. Reed \& D. R. Tanner, "Information needs and library services for the fine arts faculty", Journal of Academic Librarianship 27(3) (2001): 229-233

${ }^{16}$ S. Cowan, "Informing visual poetry", 15

${ }^{17}$ D. Chappell, "Information skills for art and design: the InfosmART project at the Glasgow School of Art", SCONUL Focus 47 (2009): 12, Available http://www.sconul.ac.uk/page/focus-47

${ }^{18}$ Association of College \& Research Libraries, Visual Literacy Competency Standards

${ }^{19}$ S. Cowan, "Informing visual poetry", 18

${ }^{20} \mathrm{~F}$. Hatt, "Towards a rationale for library user education in art and design", in User Education in Art and Design: Theory into Practice, ed. M. Avann \& K. Wood (London: Art Libraries Society, 1980), 9

${ }^{21}$ D. C. Stam, "How art historians look for information", Art Documentation 16(2) (1997): 30

22 D. C. Stam, “Artists and art libraries", Art Libraries Journal 20(2) (1995): 21

${ }^{23}$ S. Cowan, "Informing visual poetry", 14

${ }^{24}$ M. Avann \& K. Wood, 'Theory into practice', in User Education in Art and Design: Theory into Practice, ed. M. Avann \& K. Wood (London: Art Libraries Society, 1980), 11-13

${ }^{25}$ S. Cowan, "Informing visual poetry", 15

${ }^{26}$ D. Bawden, "Information systems and the stimulation of creativity", Journal of Information Science 12(5) (1986): 203-216

${ }^{27}$ P. Pacey, "How art students use libraries - if they do", Art Libraries Journal 7 (1982): 33-38

${ }^{28}$ Rockenbach \& Fabian, "Visual literacy", 30

${ }^{29}$ D. Schiff, “Information behaviors of deaf artists”, Art Documentation 29(2) (2010): 44-47

${ }^{30}$ S. Cowan, "Informing visual poetry", 17

${ }^{31}$ Q. G. Jiao \& A. J. Onwuegbuzie, "Identifying library anxiety through students' learning-modality preferences", Library Quarterly 69(2) (1999): 202-216

${ }^{32}$ C. Van Zijl \& E. M. Gericke, "Information seeking patterns of artists and art scholars at the Vaal Triangle Technikon", South African Journal of Library and Information Science 66(1) (1998): 24, Available http://sajlis.journals.ac.za/pub/article/view/1451 
${ }^{33}$ C. Rom \& E. A. Lantz, "Embedding library instruction in the design curriculum", Art Documentation, 7(4) (1988): 137-139

${ }^{34}$ P. Frank, "Student artists in the library: an investigation of how they use general academic libraries for their creative needs", Journal of Academic Librarianship 25(6) (1999): 445-455

${ }^{35}$ K. Greer, "Art students and information literacy activities", College and Research Libraries News, 77(5) (2016): 231

${ }^{36}$ L. Bliss \& B. Rockenbach, "Persuading architecture faculty that library instruction is essential: a Yale case study", Art Documentation 21(2) (2002): 22

${ }^{37}$ H. A. Pisciotta, "Let's talk: an approach to bibliographic instruction for the studio major - part one", Art Documentation 8(1) (1989): 24-25

${ }^{38}$ Van Zijl \& Gericke, "Information seeking patterns", 23-33, and, C. Van Zijl \& E. M. Gericke, "Methods used by South African visual artists to find information", Mousaion 19(1) (2001): 3-24

${ }^{39}$ P. Lo \& W. Chu, "Information for inspiration: understanding information-seeking behaviour and library usage of students at the Hong Kong Design Institute", Australian Academic and Research Libraries 46(2) (2015): 101120

${ }^{40}$ Schiff, "Information behaviors", 44-47

${ }^{41}$ Van Zijl \& Gericke, “Information seeking patterns”, 23-33

${ }^{42}$ L. Graveline, "Library services to the African American art community", Art Documentation 17(2) (1998): 8-9

${ }^{43}$ C. Pawley, "Information literacy: a contradictory coupling”, Library Quarterly 73(4) (2003): 445

${ }^{44}$ D. A. Walczak, D. L. Sammet \& M. E. Reuter, "A program for introducing information literary to applied art and design students", Communications in Information Literacy 3(2) (2009): 194, Available http://www.comminfolit.org/index.php?journal=cil\&page=article\&op=view\&path\%5B\%5D=Vol3-2009AR11

${ }^{45}$ A. Halverson \& J. Volker, "Information literacy in the electronic arts library: strategies for the hybrid professional”, IFLA Journal 26(2) (2000): 120-122

${ }^{46}$ Gregory, "Under-served or under-surveyed", 58

${ }^{47}$ Avann \& Wood, "Theory into practice", 11

${ }^{48}$ Rom \& Lantz, “Embedding library instruction”, 138

${ }^{49}$ A. Halverson, "Confronting information literacy in an academic arts library", Art Documentation 27(2) (2008): 34-38

${ }^{50} \mathrm{D}$. Johnson, "An integrated bibliographic instruction program for the architectural studies program at Clemson University: planning and early implementation", Art Reference Services Quarterly 1(2) (1993): 21-29, and, S. E. McCleskey \& D. J. Allison, "Collaboration for service learning in architectural education", Art Documentation 19(1) (2000): 40-43

${ }^{51}$ L. W. Stylianopoulos, "It's all in the company you keep: library skills credit courses in the art library", Art Documentation 22(1) (2003): 29-32 
52 R. Vecchiola, “Using ARLIS/NA 'Information Competencies for Students in Design Disciplines' in course integrated information literacy instruction at Washington University in St Louis", Art Documentation 30(1) (2011): 74-78

${ }^{53}$ Greer, "Art students", 231

${ }^{54}$ Bliss \& Rockenbach, "Persuading architecture faculty", 21-24

${ }^{55} \mathrm{C}$. McGuinness, "Exploring strategies for integrated information literacy: from academic champions to institution-wide change", Communications in Information Literacy 1(1) (2007): 30-31, Available http://www.comminfolit.org/index.php?journal=cil\&page=article\&op=view\&path\%5B\%5D=Spring2007AR3

${ }^{56}$ Rom \& Lantz, “Embedding library instruction”, 139

${ }^{57}$ A. Zanin-Yost \& E. Tapley, "Learning in the art classroom: making the connection between research and art", Art Documentation 27(2) (2008): 44

${ }^{58}$ A. Haines, "Out in the left field: the benefits of field librarianship for studio arts programs", Art Documentation 23(1) (2004): 18-20

${ }^{59}$ F. Salisbury \& J. Ellis, "Online and face-to-face: evaluating methods for teaching information literacy skills to undergraduate arts students", Library Review 52(5) (2003): 209-217

${ }^{60}$ Walczak, Sammet \& Reuter, "A program for introducing", 194

${ }^{61}$ Stylianopoulos, "It's all in the company", 29-32

${ }^{62}$ Halverson, "Confronting information literacy", 36

${ }^{63}$ Bliss \& Rockenbach, "Persuading architecture faculty", 21-24

${ }^{64}$ Zanin-Yost \& Tapley, “Learning in the art classroom”, 40-44

${ }^{65}$ Association of College \& Research Libraries, Information Literacy Competency Standards for Higher Education (Chicago: ACRL, 2000), Available http://www.ala.org/acrl/standards/informationliteracycompetency

${ }^{66}$ Chappell, "Information skills", 12-15

${ }^{67}$ Quality Assurance Agency, UK Quality Code for Higher Education: Subject Benchmark Statement for Art and Design (Gloucester: QAA, 2008), Available http://www.qaa.ac.uk/en/Publications/Documents/Subjectbenchmark-statement---Art-and-design-.pdf

${ }^{68}$ ARLIS/NA, Information Competencies for Students in Design Disciplines (Oak Creek WI: ARLIS/NA, 2006), Available https://www.arlisna.org/publications/arlis-na-research-reports/148-information-competencies-forstudents-in-design-disciplines

${ }^{69}$ SCONUL, Seven Pillars of Information Literacy (London: SCONUL, 2011), Available http://www.sconul.ac.uk/page/seven-pillars-of-information-literacy

70 Vecchiola, "Using ARLIS/NA", 75

${ }^{71} \mathrm{H}$. Ball et al., Core Competencies and Core Curricula for the Art Library and Visual Resources Professions (Oak Creek WI: ARLIS/NA, 2006)

72 Walczak, Sammet \& Reuter, “A program for introducing”, 193-203 
${ }^{73}$ Halverson, "Confronting information literacy", 36

${ }^{74}$ Salisbury \& Ellis, “Online and face-to-face”, 215

${ }^{75}$ K. M. Wayne, “Form follows information", Journal of Architectural Education 49(4) (1996): 271

${ }^{76}$ Salisbury \& Ellis, "Online and face-to-face”, 211

77 D. L. Kirkpatrick, Evaluating Training Programs: The Four Levels, Second edition (San Francisco: BerrettKoehler, 1998)

${ }^{78}$ Salisbury \& Ellis, "Online and face-to-face”, 212

${ }^{79}$ Salisbury \& Ellis, "Online and face-to-face”, 214 